\title{
DIAGNÓSTICO CITOPATOLÓGICO EM NEOPLASIAS MAMÁRIAS DE CADELAS: REVISÃO DE LITERATURA
}

\author{
RISATI, Ana Carolina ${ }^{1}$ \\ DANEZE, Edmilson Rodrigo ${ }^{2}$ \\ MAGALÃES, Geórgia Modé ${ }^{3}$
}

RESUMO: A neoplasia da glândula mamária é o segundo tumor mais frequente em cães, embora, nas cadelas seja a mais comumente encontrada. Estima-se que a incidência de malignidade de neoplasias mamárias no Brasil seja de $68,4 \%$ a $73,4 \%$ na espécie canina. Nesse sentido, todo o aumento de volume do tecido mamário em cadelas deve ser avaliado para possível diagnóstico de neoplasias, observando-se a coloração da pele, a presença de lesões, secreções e o tamanho das mamas. A citologia por aspiração com agulha fina (CAAF) pode indicar se a formação é ou não neoplásica, porém nem sempre é fácil a interpretação. Contudo, salienta-se sua importância na distinção entre processos inflamatórios, hiperplásicos, neoplásicos, o estabelecimento do prognóstico da neoplasia e a identificação de locais de metástase, com vista à rápida ação no tratamento e monitorização de possíveis recidivas locais. Na literatura veterinária, quando se avaliam as duas técnicas, os resultados demonstram que a histopatologia proporciona um diagnóstico definitivo, por proporcionar uma visão de conjunto, onde a arquitetura tecidual está completa.

Palavras-chave: Morfologia. Câncer. Metástase. Citologia. Histopatologia.

\section{CYTOLOGICAL DIAGNOSIS IN MAMMARY NEOPLASMS OF FEMALE DOGS: A REVIEW OF LITERATURE}

SUMMARY: The mammary gland cancer is the second most common tumor in dogs, although the dogs are the most commonly found. It is estimated that the incidence of malignancy of breast neoplasia in Brazil is $68.4 \%$ to $73.4 \%$ in female dogs. Accordingly, any increase in volume of the breast tissue in female dogs to be assessed for possible diagnosis of cancer, by observing the color of the skin, lesions, secretions and size of the breasts. The fine needle aspiration cytology (FNAC) can indicate whether or not the training is neoplastic, but not always easy to interpret. However, we emphasize its importance in distinguishing inflammatory, hyperplastic, neoplastic, establishing the prognosis of the neoplasia and identifying sites of metastasis, for a rapid action in the treatment and monitoring of possible local recurrence. In the veterinary literature, when evaluating both techniques, the results show that the histopathology allows a definitive diagnosis, by providing an overview of where the tissue architecture is complete.

Keywords: Morphology. Tumor. Metastasis. Citology. Hispathology.

\section{INTRODUÇÃO}

A oncologia é uma das áreas da medicina veterinária que mais evoluiu nos últimos anos, permitindo exploração em estudos tanto no âmbito clínico quanto experimental (MACEWEN, 1990). O estudo do câncer de mama em cadelas é importante devido à alta frequência com que

\footnotetext{
${ }^{1}$ Acadêmica do curso de Medicina Veterinária. Faculdade Dr. Francisco Maeda (FAFRAM/FE), Ituverava-SP

${ }^{2}$ Médico Veterinário. Programa de Aprimoramento em Clínica e Cirurgia Veterinária. Faculdade Dr. Francisco Maeda (FAFRAM/FE), Ituverava-SP.

${ }^{3}$ Médica Veterinária. Professora Doutora. Faculdade Dr. Francisco Maeda (FAFRAM/FE), Ituverava-SP
} 
surgem na rotina de atendimento, constituindo a segunda forma mais comum de neoplasias nessa espécie (VAIL; MACEWEN, 2000; DE NARDI et al., 2002; SOUZA et al., 2006).

As cadelas devem ser avaliadas considerando a idade, histórico reprodutivo e sinais clínicos, incluindo a presença de edemas mamários e aumento de linfonodos regionais (CASSALI et al., 2006). Para se atribuir um diagnóstico e estimar um prognóstico a uma cadela com neoplasia mamária, é necessária a remoção cirúrgica da mesma (CHANG et al., 2005) seguindo-se a caracterização do tipo histológico, do grau de malignidade, o estadiamento clínico, a determinação do tamanho da lesão, a existência de metástase em linfonodos regionais e a presença de metástases distantes.

Tanto para o clínico quanto para o proprietário a opção do uso da citopatologia se mostra vantajosa, pois esta técnica pode ser feita de forma rápida, fácil, com baixo custo e pouca invasividade quando comparada a outras técnicas de diagnóstico. Outra vantagem é a possibilidade de sua realização sem a necessidade de sedação dos pacientes, permitindo a colheita de material de linfonodos, pele, glândulas (LAVALLE et al., 2003; ROCHA, 2008).

Nesse sentido, a presente revisão tem por objetivo expor o uso e a aplicabilidade técnica de citopatologia no diagnóstico de neoplasias mamárias em cadelas.

\section{ANATOMIA DA GLÂNDULA MAMÁRIA}

As glândulas mamárias correspondem ao produto de glândulas sudoríparas modificadas (SOARES, 2003). A cadela possui, normalmente, cinco pares de glândulas mamárias: torácicas cranial e caudal; abdominais cranial e caudal; e inguinais. Os três primeiros pares estão interligados por uma rede de drenagem linfática em comum, que se estende para os linfonodos axilares direito e esquerdo. Os dois últimos pares interligam-se por uma rede de drenagem linfática para os linfonodos inguinais superficiais direito e esquerdos (DYCE et al., 1997; TYLER, 2000). As glândulas abdominais craniais podem drenar para os linfonodos axilar acessório e inguinal superior (ZUCCARI et al., 2001a). A glândula mamária é irrigada por artérias epigástricas superficiais, vasos ilíacos segmentares e circunflexos, artérias perineal, perivulvar e artérias torácicas internas, sendo que o fluxo sanguíneo venoso se encontra paralelamente ao arterial em quase todo o sistema (TYLER, 2000).

Os tetos ou mamilos possuem forma cônica, são ligeiramente achatados lateralmente e não possuem pêlos, os quais se encontram presentes apenas na base e na pele da glândula mamária. É possível observar, a olho nu, os orifícios do canal do teto, exceto em raças pequenas, sendo o seu número variável entre 4 a 22 , o que lhe confere um aspecto de peneira (SCHUMMER et al., 1981; DYCE et al., 1997; BARONE, 1999). 
As mamas abdominais caudais e inguinais são, sem dúvida, aquelas onde se detectam neoplasias com maior frequência, possivelmente por serem aquelas que têm maior quantidade de parênquima mamário. De acordo com Misdorp (2002), aproximadamente 2/3 das neoplasias mamárias caninas apresentaram envolvimento do $4^{\circ}$ e $5^{\circ}$ pares de glândulas, enquanto que o primeiro par tem apresentado baixa incidência.

\section{NEOPLASIAS MAMÁRIAS}

Com a evolução da medicina veterinária, a oncologia é uma especialidade que se desenvolveu bastante (HAHN; RICHARDSON, 1995). O termo neoplasia associa-se a uma mutação genética caracterizada pela proliferação desordenada e persistente de células de qualquer tecido do organismo, a qual não responde aos seus mecanismos normais de controle (KUMAR et al., 2004).

As neoplasias de cães e gatos são modelos apropriados e válidos ao estudo da biologia do câncer, assim como para testar agentes terapêuticos, já que os animais de estimação têm neoplasias com apresentação histopatológica e comportamento biológico similares àqueles que acometem os humanos (MACEWEN, 1990).

Depois das neoplasias cutâneas primárias (MOULTON et al., 1970; NERURKAR et al., 1989; ZANINOVIC; SIMCIC, 1991), as neoplasias da glândula mamária são o segundo tipo neoplásico mais frequente em cães, embora, nas cadelas seja o mais comumente encontrado (STRATMANN et al., 2008). A incidência de neoplasias mamárias em macho é de um para cada noventa e nove fêmeas (MISDORP, 2002; RUTTEMAN; KIRPENSTEIJN, 2003). Comparando com a mulher, as neoplasias mamárias de cadelas têm uma incidência três vezes superior (CASSALI et al., 2007). Estudos recentes na Suécia, em uma amostra de 80.000 cadelas, a incidência anual foi de 111 casos de neoplasias mamárias por cada 10.000 animais (EGENVALL et al., 2005).

Sabe-se que a probabilidade de desenvolvimento de neoplasias mamárias aumenta com a idade do animal, sendo a idade média de manifestação, nas cadelas, entre nove e 11 anos (PELETEIRO, 1994; LANA et al., 2007), sendo rara a manifestação em cadelas com idade inferior a cinco anos (JOHSTON et al., 2001). Egenvall et al. (2005) verificaram uma incidência de $1 \%$ aos seis anos de idade, $6 \%$ aos oito anos de idade e $13 \%$ aos 10 anos de idade. Segundo Furlani et al. (2008), a exposição a agentes carcinogênicos se eleva de acordo com a longevidade do animal, além do que os animais com idades mais avançadas possuem o sistema imune comprometido, aumentando os riscos de desenvolvimento neoplásico. 
Estima-se que a incidência de malignidade de neoplasias mamárias no Brasil seja de 68,4\% (DE NARDI et al., 2002) a 73,4\% (OLIVEIRA-FILHO et al., 2010). Nos Estados Unidos a incidência de malignidade é de 50\% a 60\%, sendo $40 \%$ das neoplasias mamárias classificadas em adenocarcinomas, 50\% mistos e 10\% de outros tipos histológicos (FERGUSSON, 1985).

Cadelas das raças Poodle, Cocker Spaniel Inglês, Britany Spaniel, Pastor Alemão, Setter Inglês, Pointer, Fox Terrier e Boston Terrier, constituem o grupo de risco de incidência de neoplasias mamárias. Acredita-se que o Chihuahua e Boxer sejam raças que apresentavam baixo risco, sendo esta última acometida geralmente em idade mais precoce. A incidência é menor em cadelas de raças mestiças quando comparadas as de raças puras (KNAPP et al., 2004).

A obesidade em fêmeas com um ano de idade ou submetidas a uma dieta caseira com carne bovina ou suína aumentam o risco de desenvolver neoplasia mamária (PELETEIRO, 1994; JOHNSTON et al., 2001; KNAPP et al., 2004). A alimentação feita com base em comida caseira, que geralmente apresenta elevados teores de gordura insaturada quando comparada com a comida comercial, foi associada a uma maior prevalência de neoplasias e displasias mamárias (RUTTEMAN; KIRPENSTEIJN, 2003). A ideia de a obesidade ser fator predisponente para ocorrência de neoplasias mamárias é comprovada pelo fato de que cadelas esterilizadas entre nove e 12 meses de idade com peso leve estão menos predispostas a terem esse tipo de neoplasia (KNAPP et al., 2004).

Não há evidências conclusivas de que ciclos estrais irregulares ou pseudociese possam originar neoplasias, mas o estrógeno endógeno pode contribuir na patogênese (FERGUSSON, 1985; WITHROW, 1992). Entretanto, a ovariohisterectomia (OHE) antes do primeiro cio diminui a incidência de neoplasias para $0,5 \%$, após o primeiro cio para $8 \%$ e após o segundo cio para $26 \%$, não havendo efeito sobre o desenvolvimento neoplásico em cadelas esterilizadas após 30 meses de idade (SCHNCIDER et al., 1969), sendo este efeito protetor permanecendo desaparecido, ou protege apenas de forma moderada, quando a OHE é realizada em cadelas com mais de dois anos e meio de idade (MORRISON, 1998; RUTTEMAN; KIRPENSTEIJN, 2003). Este fato sugere que o desenvolvimento das neoplasias mamárias é dependente de influências endócrinas e que a manipulação hormonal poderá ser um instrumento favorável no tratamento da neoplasia (SORENMO et al., 2000).

Apesar da comprovada influência hormonal, a administração prolongada de estrogênios em cadelas não aumenta a incidência de neoplasias da glândula mamária; porém, a administração de progesterona pode originar a formação de nódulos benignos (CHUN; GARRETT, 2005). Existem numerosos estudos imuno-histoquímicos que comprovam a existência de receptores de estrogênio e progesterona, tanto no tecido mamário normal, como na maioria das neoplasias mamárias (HENSON, 2003). 
A pseudociese é considerada um fenômeno fisiológico do ciclo estral da cadela. Contudo, esses animais geralmente apresentam crescimento de alvéolos glandulares mamários, além da proliferação das células mioepiteliais. Assim considerando-se que o leite retido cronicamente pode conter compostos químicos que tem efeito carcinogênico sobre o epitélio adjacente, estes podem atuar como indutores e ou promotores de neoplasias mamárias (TANAKA, 2003).

A maioria dos cães com neoplasias mamárias são clinicamente saudáveis no momento do diagnóstico e os tumores podem ser identificados pelo proprietário ou profissional durante um exame físico de rotina (SORENMO, 2006). Antes de realizar o exame físico das glândulas mamárias, é importante conhecer algumas informações sobre o animal, tais como espécie, raça, nome, idade, peso. Na anamnese procura-se resgatar todo o histórico reprodutivo do animal, questionar sobre quantos partos a fêmea já teve, sobre cirurgias ou exames realizados anteriormente, informações sobre o aparecimento e duração dos sinais clínicos, uso ou não de anticoncepcional, sobre tratamentos realizados e evolução (MACEWEN; WHITROW, 1996; FEITOSA, 2008).

Todo aumento do tecido mamário deve ser avaliado para possível diagnóstico de neoplasias. Os aumentos generalizados não associados à pseudogestação, lactação ou mastite, devem receber atenção especial (ZUCCARI et al., 2001a). Importante dizer que um único animal pode apresentar mais do que um tipo de neoplasia (ALLEN et al., 1986), sendo que a presença de múltiplos nódulos em glândulas de um ou de ambos os lados é um achado comum.

O exame físico das glândulas mamárias inicia-se com a inspeção do paciente, onde se observa a coloração da pele, a presença de lesões, secreções, o número e o tamanho das mamas. A palpação fica mais fácil de ser realizada com os animais em decúbito lateral e deve iniciar-se das glândulas aparentemente sadias para as visivelmente alteradas e todos os pares de glândulas devem ser palpados (FEITOSA, 2008). Sendo este orientado à partir da determinação da extensão da doença e estabelecimento do estágio clínico (STONE, 2003), e concluí-se relacionando-o aos achados de histórico, exames físico e complementar, como citopatologia aspirativa e histopatologia (ARGYLE, 1999).

As neoplasias, na maioria das vezes, apresentam estruturas caracterizadas por cistos, geralmente com forma de lóbulos, castanhos acinzentados e com textura firme (PELETEIRO, 1994). Podem revelar a presença de constituintes cartilaginosos ou ósseos, como osteoblastos e osteoclastos (HENSON, 2003). Macroscopicamente podem atingir $20 \mathrm{~cm}$, contudo, geralmente, não ultrapassam os $10 \mathrm{~cm}$. Conforme Peleteiro (1994), estes são facilmente reconhecidos como massas de superfície bem circunscritas, podendo ser móveis ou aderentes.

Geralmente, o rápido crescimento, a invasão local dos tecidos e a ulceração são características de neoplasias malignas (MACEWEN; WITHROW, 1996). Neoplasias malignas da 
glândula mamária podem gerar metástases para vários órgãos, sendo os nódulos linfáticos regionais e os pulmões os mais frequentemente afetados (BREARLEY, 1989; LANA et al., 2007). Em estágios avançados as metástases pulmonares produzem sinais clínicos (THRALL, 1979; BRODEY et al., 1983; NELSON; SELLON, 2005; HOFFMANN et al., 2013).

De acordo com Cowell; Tyler (1989a,b), a técnica para obtenção de espécimes e preparação de lâminas varia conforme a localização anatômica e as características do tecido neoplásico, do animal e das anormalidades clínicas desencadeadas pela neoplasia. As amostras podem ser obtidas de diversas maneiras, através de aspirados com agulha fina (CAAF), da impressão de tecidos sólidos ("imprint"), uso de "swab" e da técnica esfoliativa (SUSANECK, 1983; MORRIELLO; ROSENTHAL, 1990, WEELLMAN, 1996, MONTES, 1997).

Quanto ao prognóstico das neoplasias mamárias em cadelas, este depende do seu tipo histológico; da sua dimensão, tendo pior prognóstico os tumores com dimensões superiores a 3,0 cm de diâmetro; do envolvimento dos linfonodos regionais; da evidência histológica de invasão vascular ou linfática; da presença de ulceração; e da existência de metástases (CHUN et al., 2005). Segundo Fergusson (1985) e Soave et al. (2008), no estabelecimento do prognóstico, em cães com neoplasias mamárias, um exame radiográfico completo do tórax deve ser realizado para observar se há presença de metástase pulmonar, sendo realizado preferencialmente em três projeções (lateral direita e esquerda e ventrodorsal) (JOHNSON, 2006). Um achado radiográfico indicativo de metástase pulmonar pode ser descrito como padrão radiográfico intersticial estruturado ou não estruturado e, mais raramente, em padrão alveolar (BURK; FEENEY, 2003; LAMB, 2007). Caso haja alguma suspeita de acometimento de linfonodos inguinais a ultrassonografia abdominal será indicada para procura de metástase em linfonodos sub lombares e órgãos abdominais (HARVEY, 2005). Em casos de claudicação e/ou edema de membros é necessário realizar radiografias da área afetada em busca de metástase óssea (BIRCHARD; SERDING, 1998).

Chun e Garrett (2005) afirmaram que das neoplasias mamárias malignas, cerca de 50\% podem recidivar ou causar metástase depois da primeira ressecção cirúrgica. Contudo, no que se refere a neoplasias desenvolvidas em cadeias mamárias independentes, não existe uma correlação significativa quanto ao diagnóstico histológico.

A procura por tratamento em animais domésticos com neoplasias vem aumentando e os métodos alopáticos (quimioterapia) são a maneira mais efetiva de combater as formas malignas (MORRIS; DOBSON, 2007); porém algumas reações indesejáveis podem ocorrer devido à quimioterapia, como uma forte anorexia e/ou leve mielossupressão (STONE, 2003).

Com o uso de drogas quimioterápicas, a incidência de metástases é diminuída e o animal passa a ter uma maior sobrevida em relação a animais não expostos a nenhum tipo de tratamento. 
Os principais protocolos utilizados na prática médico veterinária associam duas ou três drogas (como por exemplo, ciclofosfamida e doxorrubicina); no entanto, a escolha destas deve basear-se em critérios clínicos e/ou histopatológicos (CIRILLO, 2008).

A mastectomia pode ocorrer em diferentes localizações e ter abrangência variada, pois depende da glândula ou das glândulas afetadas e do tamanho da neoplasia. A cirurgia pode se resumir na excisão de uma glândula de um dos lados, ou até a remoção de todas as mamas de um lado. Em casos muitos graves, há a necessidade de mastectomia radical bilateral (JOHNSON, 2006). Processos cirúrgicos radicais devem ser fracionados para diminuir a ferida cirúrgica e a tensão nas linhas de sutura (HEDLUND, 2005).

É importante que todos os linfonodos sejam avaliados, sendo eliminados caso possuam alguma infiltração, evitando assim a transferência de células neoplásicas para áreas não afetadas (QUEIROGA; LOPES, 2002).

A homeopatia vem sendo bastante utilizada na Medicina Veterinária. Alguns medicamentos com grande potencial de cicatrização e ação antisséptica podem ser bastante eficazes no pós-operatório em casos de exérese de neoplasias mamárias, como é o caso da Arnica montana, Calendula officinalis e Silicea, favorecendo o prognóstico do paciente, além de ser de fácil aplicação e menor custo (PINTO, 2000).

\section{DIAGNÓSTICO CITOPATOLÓGICO}

A citologia aspirativa com agulha fina (CAAF) pode indicar se a formação é ou não neoplásica, porém nem sempre é fácil a interpretação. Indica-se a CAAF para acessar linfonodos regionais em suspeita de metástase (MORRIS et al., 2007). Normalmente, é através da biópsia que se confirma o diagnóstico, sendo ela realizada junto com a excisão do nódulo como parte do procedimento de tratamento.

Em medicina humana, a citopatologia é empregada desde o século XIX (CASTILLO et al., 1988; CARVALHO, 1993). Cassali et al. (2007), referem que esta técnica começou a ser utilizada por Paget em 1854, para observar aspirados de tumores mamários ao microscópio. Discordantemente, Miralles e Buesa (1988) afirmaram que a CAAF começou a ser utilizada por Griek e Gay no ano de 1904, aplicando esta técnica para o diagnóstico de tripanossomíases em linfonodos. Em 1914, o médico Eward aplicou esta técnica para diagnosticar a doença de Hodgkin. Em 1867, Leucke e Klebs estudaram células de líquido ascítico em pacientes com tumores ovarianos, enquanto Papanicolaou iniciou suas pesquisas sobre citologia esfoliativa, tendo estabelecido em 1928 o diagnóstico de carcinoma uterino a partir da secreção vaginal de mulheres (BOON et al., 1982; FELIZZOLA, 1995).

Nucleus Animalium, v.6, n.1, maio 2014 
Dentro da medicina veterinária brasileira, este método diagnóstico é relativamente novo, ganhando algum incremento no final do ano de 1980 (SILVEIRA, 1988; GUEDES et al., 1997). No entanto, o atraso de seu uso na prática clínica deveu-se, sobretudo, à ignorância da sua utilidade diagnóstica, assim como à insegurança associada à sua interpretação (MEYER, 1996).

De acordo com Henson (2003), as neoplasias mamárias apresentam características específicas, uma vez que massas de grandes dimensões podem apresentar diferente constituição em locais diferentes, com grande heterogeneidade tecidual, surgindo locais de reação inflamatória, cistos e nódulos neoplásicos. Assim, nos esfregaços obtidos a partir de uma neoplasia mamária, podem ser encontradas células de reação inflamatória, conteúdo cístico e células neoplásicas de origem epitelial.

Apesar disso, esta técnica é considerada muito útil na identificação dos linfonodos suspeitos de metástases. Por outro lado, a distinção entre benigno e maligno não implicará mudanças na conduta operatória (ZUCCARI et al., 2001b). O exame citológico da maioria dos tumores mamários revela um fundo contendo uma quantidade variável de sangue, material proteináceo e/ou basofílico, adipócitos e células espumosas (HENSON, 2003).

A punção aspirativa de massas neoplásicas teve uma adesão inicial interessante, seguida de algum descrédito, porque se acreditava que ao puncionar essas massas poder-se-ia conduzir à dispersão de células neoplásicas pelos tecidos (MEYER, 1996), sendo isso considerado um fator de risco. Contudo, sabe-se hoje, que a CAAF é uma técnica segura do ponto de vista da possível dispersão de células neoplásicas, tratando-se de uma técnica muito pouco invasiva, simples, de rápida execução, relativamente indolor e fornece informações muito úteis sem a necessidade de anestesia geral, e de todos os riscos anestésicos inerentes e pós-cirúrgicos, assim como as complicações tardias associadas (MAGALHÃES et al., 2001).

A CAAF induz injúria tecidual mínima, não havendo necessidade de se proceder à anestesia do animal. Por ser mínima a lesão provocada pela agulha fina, a predisposição para ocasionar metástases, em casos de neoplasias malignas, torna-se insignificante em comparação com a biópsia cirúrgica. Dentre os principais objetivos da citopatologia, salienta-se a distinção entre processos inflamatórios, hiperplásicos e neoplásicos, o estabelecimento de um prognóstico e a identificação de locais de metástase, com vista à rápida ação no tratamento e monitorização de possíveis recidivas locais (MILLS; GRIFFITHS, 1984).

As principais vantagens do exame citopatológico são a rapidez e a simplicidade com que são realizados; proporcionando diagnósticos sugestivos, sem risco anestésico, além de ser bastante acessível do ponto de vista econômico. De um modo geral, as amostras citopatológicas são facilmente obtidas, já que muitas formas de colheita são pouco invasivas e o grau de morbidade e/ou complicações tardias, associadas com as mesmas, são mínimas (COUTO, 1994). 
As principais complicações da citopatologia podem ser hemorragia, infecção, injúria ao tecido adjacente e disseminação de células neoplásicas: fatos considerados raros (WELLMAN, 1990).

O sucesso da CAAF depende das diversas fases de condução da técnica, desde a obtenção da amostra, da preparação da lâmina e sua coloração, até o exame citoscópico do material aspirado. As dificuldades impostas a um ou mais passos da técnica irão afetar os resultados que podem ser obtidos com a prática da CAAF. Alguns autores não consideram a CAAF como a técnica de diagnóstico mais indicada, pois a maioria das neoplasias mamárias de cadelas são mistas, pelo que há necessidade de vários pontos de aspiração (PELETEIRO, 1994; ZUCCARI et al., 2001b).

Peleteiro (1994) afirmou ser difícil o diagnóstico correto das neoplasias mamárias caninas, utilizando-se apenas das técnicas citológicas, e faz referência a um índice de diagnósticos corretos abaixo da média humana referida por vários autores, entre eles Griffiths et al. (1984) e Allen et al. (1986), sugerindo que o mais difícil é o diagnóstico de uma lesão benigna, pois geralmente é pobre em células e pode conter vários elementos típicos de uma mama normal como adipócitos, sangue e algumas células de revestimento ductal, geralmente dispostas em placas.

No entanto, a sua aplicação de forma quase cotidiana em medicina veterinária só se verificou nos últimos vinte anos (CASSALI et al., 2007). Apresentando diagnóstico sugestivo na ordem de $86,4 \%$ quando comparada ao exame histopatológico das principais neoplasias dos animais domésticos (BRACARENSE et al., 1993; CASTRO et al., 1993; GUEDES et al., 1997). As informações determinadas por esse método direcionam as condutas clínicas (quimioterapia, radioterapia) e cirúrgicas (MAGALHÃES et al., 2001).

Feichter et al. (1997), observaram que a CAAF é um bom método de triagem para a realização da biópsia, pois sua acurácia varia entre $82-91 \%$ de eficácia em comparação ao resultado da histologia. A técnica é comumente usada na punção de massas superficiais e discerníveis radiograficamente (SAXE et al., 2001).

Com o advento da ultrassonografia, a punção aspirativa eco-guiada tem ganhado o seu espaço e aplicabilidade (MEYER, 1996), permitindo aspirar células de lesões não palpáveis (VALLI, 1988).

Segundo Magalhães et al. (2001), há necessidade de avaliações comparativas dessa técnica com a histopatologia para uma gama maior de neoplasias nos animais domésticos. Além disso, percebe-se a necessidade de introdução de novas técnicas de colorações específicas mais conclusivas para as neoplasias, a partir das técnicas histológicas de coloração.

Quanto à capacidade da CAAF em permitir um diagnóstico correto preliminar, há bons indicadores bibliográficos da sua real segurança como meio de ajuda diagnóstica. Na experiência 
de O’Rourke (1983) e Meyer; Franks (1986), a segurança da informação obtida pela citopatologia depende da qualidade da técnica e confecção das lâminas. As células obtidas por CAAF são dispostas sobre as lâminas, preferencialmente em monocamada, permitindo a obtenção dos detalhes (PELETEIRO et al., 2006). A coloração e a interpretação da amostra também são de fundamental importância para o sucesso da citopatologia (CUNHA, 1987; MEYER, 1987), cuja precisão pode variar de 63 a 97\%, dependendo do tipo e da localização da neoplasia, e da perícia do citopatologista (MILLS; GRIFFITHS, 1984).

Magalhães et al. (2001) mencionam que, em determinadas situações, o diagnóstico citopatológico é mais fácil do que o exame histopatológico, citando os exemplos das granulações metacromáticas intracitoplasmáticas dos mastocitomas, dos detalhes celulares nas lesões linfoproliferativas e dos grânulos de melanina nos melanomas. Afirmam ainda que em determinados sarcomas e linfomas, o exame citopatológico por meio de CAAF possui melhor eficácia para o diagnóstico do que a histopatologia. Segundo Cassali et al. (2011), o exame citológico pode ser útil para a exclusão de diagnósticos diferenciais, tais como mastite, lipomas e mastocitomas, entre outros. No entanto, uma das principais limitações da citopatologia relacionase com a descrição das neoplasias, que não é específica, sendo as lesões reconhecidas apenas como carcinoma ou sarcoma (MAGALHÃES et al., 2001).

$\mathrm{Na}$ literatura veterinária, estudos comparativos entre as duas técnicas demonstram que a histopatologia proporciona um diagnóstico definitivo, por permitir uma visão de conjunto, onde a arquitetura tecidual está completa (BARTON, 1983; MEYER; FRANKS, 1986; HEWICKER et al., 1990; TVEDTEN, 1994).

Segundo a classificação histológica da Organização Mundial de Saúde (OMS) (MISDORP et al., 1999) as neoplasias mamárias de canídeos e dos felídeos, podem ser classificados em quatro grandes categorias: malignos, benignos, hiperplasias/displasias mamárias e outros tumores não classificados.

A malignidade é desenvolvida a partir de tecidos neoplásicos mistos como carcinomas, mioepiteliomas malignos, condrossarcomas, osteossarcomas e dificilmente ocorrem a partir de um carcinoma com algum outro tipo maligno (MOULTON, 1990). Foi comprovado que tanto os componentes epiteliais quanto as células mioepiteliais apresentam o mesmo DNA, sugerindo a possibilidade de ambos os componentes serem originados de uma célula-tronco totipotente (GÄRTNER et al., 1999).

Nas neoplasias mamárias caninas há muita discordância entre os diagnósticos, com muitas classificações morfológicas sendo propostas (BENJAMIN et al., 1999). Provavelmente as mais usadas mundialmente são as de Moulton (1990) e da OMS (MISDORP et al., 1999), as quais apresentam algumas divergências entre si. Uma das diferenças entre esses autores está na 
classificação do carcinoma complexo, onde pela OMS refere-se ao carcinoma como proliferação de células mioepiteliais e que a invasão em vasos linfáticos é considerada rara nesse tipo de neoplasia; e quando não há proliferação de células mioepiteliais o carcinoma é considerado simples (MISDORP et al., 1999). Já Moulton (1990) incluiu as neoplasias com proliferação de células mioepiteliais em mistas e em mioepiteliomas e não concorda com a divisão da OMS em complexo e simples.

As neoplasias mamárias de cadelas também podem ser classificadas por estágio, segundo o comportamento do tumor primário $(\mathrm{T})$, envolvimento dos linfonodos regionais $(\mathrm{N})$, e presença ou ausência de metástase distante (M), no caso de sua ocorrência (JOHSTON, 1998). Classificar cada caso segundo o sistema TNM (tumor, linfonodo, metástase), conforme proposto pela OMS, permite estabelecer um prognóstico e planejar um tratamento.

\section{CONSIDERAÇÕES FINAIS}

As neoplasias mamárias caninas são muito frequentes em cadelas, principalmente em mamas abdominais caudais e inguinais. A melhor forma de prevenção é a esterilização com ovariohisterectomia antes do primeiro cio. O diagnóstico abrange aspectos clínicos e anatomopatológicos. A citopatologia é um método simples, não invasivo e rápido para obtenção do diagnóstico. Deve ser realizada em vários locais do nódulo, pode não ser conclusiva, mas excluem diagnósticos como mastocitomas e lipomas localizados em região de glândula mamária. A histopatologia é considerado o método de diagnóstico definitivo para neoplasias mamárias caninas, sendo a classificação de Cassali et al. (2011) a mais preconizada no Brasil.

\section{REFERÊNCIAS}

ALLEN, S. W.; PRASSE. K. W.; MAHAFFEY, E. A. Cytologic differentiation of benign from malignant canine mammary tumors. Veterinary Pathology, v.23, n.6, p.649-655, 1986.

ARGYLE, D. J. La glandula mamaria. In: SIMPSON, G. M.; ENGLAND, G. C. W.; HARVEY, M. J. Manual de reproducción y neonatología en pequeños animals. Barcelona: Harcourt, 1999. cap.5, p.69-77.

BARONE R. Anatomie Comparée dês Mamiféres Domestiques. Tomo IV- Esplanchnologie II. Paris: Vigot, 1999. v.2, p.449-500.

BARTON, C. L. Cytologic diagnosis of neoplastic disease: an Algorithm. Texas Veterinary Medicine Journal, Small Animal Medicine, v.45, n.1, p.11- 13, 1983.

BENJAMIN, S. A.; LEE, A. C.; SAUNDERS, W. J. Classification and behavior of canine mammary epithelial neoplasms based on life-span observations in beagles. Vet. Pathol., v.36, p.423-436, 1999. 
BIRCHARD, S. J.; SHERDING, R. G. Manual Saunders: clínica de pequenos animais. São Paulo: Roca, 1998. 1591p.

BOON, G. D.; REBAR, A. H.; DE NICOLA, D. B. A cytologic comparison of Romanowsky stains and Papanicolau-type stains. I. Introduction, methodology and cytology of normal tissues. Veterinary Clinical Pathology, v.11, n.1, p.22-30, 1982.

BRACARENSE, A. P. F. R. L.; REIS, A. C. F.; VIOTTI, N. M. A. Estudo comparativo entre o exame citológico e histopatológico nas neoplasias dos animais domésticos. CONGRESSO BRASILEIRO DA ANCLIVEPA, 15, 1993. Anais... Rio de Janeiro: Anclivepa, 1993. p.139.

BREARLEY, M. J. Mammary gland tumours in the dog. In Practice, v.11, p.248-253, 1989.

BRODEY, R. S.; GOLDSCHMIDT, M. H.; ROSEL, J. R. Canine mammary gland neoplasms. Journal of the American Animal Hospital Association, v.19, p.61-90, 1983.

BURK, R. L.; FEENEY, D. A. The thorax in small animal radiology and ultrasonography: a diagnostic atlas and text. 3.ed. United States of America: Saunders Elsevier Science, 2003. p.25278

CARVALHO, G. Citologia oncológica. São Paulo: Atheneu, 1993. p,290.

CASSALI et al., Consensus for diagnosis, prognosis and treatment of canine mammary tumors. Brazilian Journal of Veterinary Pathology, v.4, n.2, p.153-180, 2011.

CASSALI, G. D.et al. Evaluation of accuracy of fine needle aspiration cytology for diagnosis of canine mammary tumours: comparative features with human tumours. Cytopathology, v.18, p. 191-196, 2007.

CASSALI, G. D.et al. Evaluation of accuracy of fine needle aspiration cytology for diagnosis of canine mammary tumours: comparative features with human tumours. Cytopathology, v.18, p.191-196, 2006.

CASSALI, G. D. Patologia da glândula mamária. In: NASCIMENTO, E. F.; SANTOS, R. L. Patologia da reprodução dos animais domésticos. 2.ed. Rio de Janeiro: Guanabara Koogan, 2002. p.131-133.

CASTILLO, C. A.; CANDANOSA, E. A.; BUEN, N. A. Diagnóstico citológico em veterinaria, análisis de 3563 casos. Veterinaria México, v.19, p.211-215, 1988.

CASTRO, M. B.; MOREIRA, M. M.; CASAGRANDE, A. M.; FRANCO, S. R. V. S.; FABRIS V. E. Manifestação cutânea do tumor venéreo transmissível (TVT) em cães - relato de 2 casos. CONGRESSO BRASILEIRO DA ANCLIVEPA, 15, 1993. Anais... Rio de Janeiro: ANCLIVEPA, 1993. p.145.

CHANG, S. C.; CHANG, C. C.; CHANG, T. J.; WONG, M. L. Prognostic factors associated with survival two years after surgery in dog with malignant mammary tumors: 79 cases (19982002). Journal American Veterinary Medicine Association, v.10, p.1625-1629, 2005.

CHUN, R.; GARRETT, L. Urogenital and mammary gland tumors. In: ETTINGER, S. J.; FELDMAN, E. C. Textbook of veterinary internal medicine. 6.ed. St. Louis, Missouri: Elsevier Saunders, 2005. p.788-789. 
CIRILLO, J. V. Tratamento quimioterápico das neoplasias mamárias em cadelas e gatas. Journal of the Health Sciences Institute, v.26, n.3, p.325-327, 2008.

COUTO, C. G. Cytology in the diagnosis of cancer. TNAVC - Proceedings in Small Animal. Clinical Pathology, p.91-93, 1994.

COWELL, R. L.; TYLER, R. D. Cytology of cutaneous lesions. Veterinary Clinics of North America: Small Animal Practice, v.19, n.4, p.769-794, 1989a.

COWELL, R. L.; TYLER, R. D. Diagnostic cytology of the dog and cat. Michigan: American Veterinary Publications, 1989b. 259p.

CUNHA, M. M. P. L. Manual de laboratório cito-histopatológico. Ministério da Saúde, Secretaria Nacional de Programas Especiais de Saúde, Divisão Nacional de Saúde MaternoInfantil, Divisão Nacional de Laboratórios de Saúde Pública, Centro de Documentação do Ministério da Saúde, Série A: Normas e Manuais Técnicos. Brasília: MS, 1987. 43p.

DE NARDI, A. B.et al. Prevalência de neoplasias e modalidades de tratamento em cães atendidos no Hospital Veterinário da Universidade Federal do Paraná. Archives of Veterinary Science, v.7, n.2, p.15-26, 2002.

DYCE, K. M; SACK, W. O.; WENSING, G. J. G. Textbook of Veterinary Anatomy. Malvern: Williams \& Wilkins, 1997. p.338-340.

EGENVALL, A.et al.Incidence of and survival after mammary tumors in a population of over 80,000 insured female dogs in Sweden from 1995 to 2002. Preventive Veterinary Medicine, v.10, n.69 (1-2), p.109-27, 2005.

FEICHTER, G. E.et al. Breast cytology. Statistical nalysis and cytohistologic correlations. Acta Cytologica, v.41, n.2, p.327-332, 1997.

FEITOSA, F. L. F. Semiologia da glândula mamária de éguas, cadelas e gatas. In: Semiologia veterinária: a arte do diagnóstico. 2.ed. São Paulo: Roca, 2008. p.321.

FELIZZOLA, C. R. Estudo comparativo de neoplasias bucais em cães - avaliação dos aspectos clínicos, da histopatologia e citologia esfoliativa. 1995. 89f. Dissertação (Mestrado em Cirurgia). Faculdade de Medicina Veterinária e Zootecnia. Universidade de São Paulo.

FERGUSSON, H. R. Canine mammary gland tumors. Veterinary Clinics of North America: Small Animal Practice, v.15, n.3, p.501-11, 1985.

FIDLER, I. J.; BRODEY, R. S. A necropsy study of canine malignant mammary neoplasms. Journal American Veterinary Medicine Association, v.151, p.710-715, 1967.

FURLANI, M. F.et al. Mastectoma canino: estudo retrospectivo. Ciência Animal Brasileira, v.9, n.1, p.242-250, 2008.

GÄRTNER, F.et al. DNA measurement and immunohistochemical characterization of epithelial and mesenchymal cells in canine mixed mammary tumours: putative evidence for a common histogenesis. The Veterinary Journal, v.158, n.1, p.39-47, 1999.

GRIFFITHS, G. L.; LUMSDEN, J. H.; VALLI, V. E. O. Fine needle aspiration cytology and histologic correlation in canine tumors. Veterinary Clinical Pathology, v.13, n.1, p.13-17, 1984. 
GUEDES, R. M. C.; NOGUEIRA, R. H. G.; TUDURY E. A. Diagnóstico citológico de lesões proliferativas e inflamatórias através da técnica de punção de tecidos com agulha fina. A Hora Veterinária, v.16, n.96, p.15-21, 1997.

HAHN, K. A.; RICHARDSON, R. C. Cancer chemotherapy: a veterinary handbook. Malvern: Williams \& Wilkins, 1995. 255p.

HARVEY, J. Glândulas mamárias. In: BOJRAB, M. J. Técnicas atuais em cirurgia de pequenos animais. 3.ed. São Paulo: Roca, 2005. p.425.

HEDLUND, C. S. Cirurgia dos sistemas reprodutivo e genital. In: FOSSUM, T. W. et al. Cirurgia de Pequenos Animais. 2.ed. São Paulo: Roca, 2005. p.611-624.

HENSON, K. L. Sistema reprodutor. In: RASKIN, R. E.; MEYER, D. J. Atlas de citologia de case e gatos. São Paulo: Roca, 2003. p.233-243.

HEWICKER, M.et al. Epidermotropes Lymphosarkom (Mycosis fungoides) beieinem Hund. Tierärztliche Praxis, v.18, n.6, p.633-639, 1990.

HOFFMANN, M. L.; MARTINS, D. B.; FETT, R. R. Carcinoma mamário com metástase pulmonar em felino - relato de caso. SEMINÁRIO INTERINSTITUCIONAL DE ENSINO, PESQUISA E EXTENSÃO, 18, 2013. Anais eletrônicos... Cruz Alta-RS: Universidade de Cruz Alta, 2013. Disponível em:

http://www.unicruz.edu.br/seminario/anais/2014/CCS/MEDICINA\%20VETERINARIA/Poster/C ARCINOMA\%20MAM\%C1RIO\%20COM\%20MET\%C1STASE\%20PULMONAR\%20EM\%2 0FELINO\%20\%96\%20RELATO\%20DE\%20C . Acesso: 15 maio 2014.

JOHNSON, C. A. Distúrbios da glândula mamária. In: NELSON, R. W.; COUTO, G. C. Medicina interna de pequenos animais. 3.ed. Rio de Janeiro: Elsevier, 2006, p.847-848.

JOHSTON, S. D.; KUSTRITZ, M. V. R.; OLSON, P. N. S. Canine and feline theriogenology. Philadelphia: WB Saunders Company, 2001. p.206-224.

KNAPP, D. W.; WATERS, D. J.; SCHMIDT, B. R. Tumores do sistema urogenital e das glândulas mamária. In: ETTINGER, S. J.; FELDMAN, E. C. Tratado de medicina interna veterinária: doenças do cão e do gato. 5.ed. Rio de Janeiro: Guanabara Koogan, 2004. p.574580 .

KUMAR, V.; FAUSTO, N.; ABBAS, A. Pathologic basis of disease. 7.ed. Pennsylvania: Elsevier Health Sciences, 2004. p.288-325.

LAMB, C. R. The canine and feline lung In: THRALL, D. E. Textbook of veterinary diagnostic radiology. 5.ed. United States of America: Saunders Elsevier, 2007. p.591-608

LANA, S. E.; RUTTEMAN, G. R.; WITHROW, S. J. Tumors of the mammary gland. In: WITHROW, S. J.; VAIL, D. M. Small animal clinical oncology. 4.ed. St. Louis: Saunders Elsevier, 2007. p.619-636.

LAVALLE, G. E.et al. Punção aspirativa por agulha fina para diagnóstico de mastocitoma em cães. Arquivo Brasileiro de Medicina Veterinária e Zootecnia, v.55, n.4, p.500-502, 2003.

MACEWEN, E. G.; WITHROW, S. J. Tumors of the mammary gland. In: WITHROW, S. J., MACEWEN, E. G. Small animal clinical oncology. 2.ed. Philadelphia: Saunders, p. 356-372, 1996. 
MACEWEN, E. G. Spontaneous tumors in dogs and cats: Models for the study of cancer biology and treatment. Cancer and Metastases Review, v.9, n.2, p.125-136, 1990.

MAGALHÃES, A. M.et al. Estudo comparativo entre citopatologia e histopatologia no diagnóstico de neoplasias caninas. Pesquisa Veterinária Brasileira, v.21, n.1, p.23-32, 2001.

MEYER, D. J. Diagnostic cytology in clinical oncology. WITHROW, S. J.; MACEWEN, E. G. Small animal clinical oncology. 2.ed. Philadelphia: WB Saunders Company, 1996.

MEYER, D. J. The management of cytology specimens. Compendium Continuing Education Practioner Veterinary, v.9, n.1, p.10-17, 1987.

MEYER, D. J.; FRANKS, P. Clinical cytology. Part I: Management for tissue specimens. Modern Veterinary Practice, v.67, p.255-259, 1986.

MILLS, J. N.; GRIFFITHS, G. L. The accuracy of clinical diagnoses by fine-needle aspiration cytology. Australian Veterinary Journal, v.61, n.8, p.269-271, 1984.

MIRALLES, T. G.; BUESA, J. M. Introduccion. In: MIRALLES, T. G.; BUESA, J. M. Puncionaspiracion con aguja fina - indicaciones, diagnóstico y correlación clínico-patológica.

Mallorca: Salvat Editores, 1988. p.1-6.

MISDORP, W. Tumors of the mammary gland. In: MEUTEN, D. J. Tumors in domestic animals. 4.ed. Iowa: Blackwell Publishing, 2002. p.575-606.

MISDORP, W.et al. Definitions and explanatory notes. In: WHO histological classification of mammary tumors of the dog and cat. Washington: Armed Forces Institute of Pathology, 1999. p.18-27.

MONTES, O. G. A. Citologia en la clinica medica de pequeños animales. JORNADAS HOSPITALARIAS DE MEDICINA VETERINARIA, 2, 1997. Anais... Buenos Aires: Universidad de Buenos Aires, 1997. p.111-117.

MORRIELLO, K. A.; ROSENTHAL, R. C. Clinical approach to tumors of the skin and subcutaneous tissues. Veterinary Clinics of North America: Small Animal Practice, v.20, n.4, p.1163-1190, 1990.

MORRIS, J.; DOBSON, J. Glândula mamária. In: Oncologia de pequenos animais. São Paulo: Roca, 2007. 312p.

MORRISON, W. B. Canine and feline mammary tumors. In: Malvern: Williams \& Wilkins, 1998. p.591-597 Cancer in dogs and cats.

MOULTON, J. E. Mammary glands. In: Tumors in domestic animals. 3.ed. Califórnia: University of Califórnia Press, 1990. p. 519-545.

MOULTON, J. E.; TAYLOR, D. D. N.; ANDERSEN, A. G. Canine mammary tumors. Veterinary Pathology, v.7, n.4, p.289-320, 1970.

NELSON, O. L.; SELLON, R. K. Pulmonary parenchymal disease. In: ETTINGER, S. J. Textbook of veterinary internal medicine. 6.ed. St Louis: Saunders, 2005. p.1241-1247.

NERURKAR, V. R.et al. Comparative pathology of canine mammary tumors. Journal of Comparative Pathology, v.101, n.4, p.389-397, 1989. 
OLIVEIRA FILHO, J. C. et al. Estudo retrospectivo de 1.647 tumores mamários em cães.

Pesquisa Veterinária Brasileira, v.30, n.2, p.177-185, 2010.

O'ROURKE, L. G. Cytologic technics: sampling, slide preparation, staining. Modern

Veterinary Practice, v.64, n.3, p.185-189, 1983.

OWEN, L. N. A comparative study of canine and human breast câncer. Investigative \& Cell Pathology, v.2, n.4, p.257-75, 1979.

PELETEIRO, M. C. Tumores mamários na cadela e na gata. Revista Portuguesa de Ciências Veterinárias, v.898, n.509, p.10-29, 1994.

PELETEIRO, M. C.et al. Diagnóstico citológico em medicina veterinária. In: CURSO DE CITOLOGIA PARA CLÍNICOS VETERINÁRIOS, 6, 2006, Lisboa. Anais... Lisboa: FMVUTL, 2006.

PINTO, F. L. Protocolo pós-operatório homeopático em mastectomia radical de cadelas e gatas. Brazilian Homeopathic Journal, v.6, n.1, p.18-21, 2000.

QUEIROGA, F.; LOPES, C. Tumores mamários caninos, pesquisa de novos factores de prognóstico. Revista Portuguesa de Ciências Veterinárias, v.97, p.119-127, 2002.

ROCHA, N. S. Exame citológico no diagnóstico de lesões da pele e subcutâneo. Clínica Veterinária, n.76, p.76-80, 2008.

RUTTEMAN, G. R.; KIRPENSTEIJN, J. Tumours of the mammary glands. In: DOBSON, J. M.; LASCELLES, B. D. X. BSAVA: Manual of canine and feline oncology. 2.ed. Gloucester: British Small Animal Veterinary Association, 2003. p. 234-242.

SAXE, A.et al. Role of sample adequacy in fine needle aspiration biopsy of palpable breast lesions. American Journal of Surgery, v.182, n.4, p.369-371, 2001.

SCHNCIDER, R.; DORN, C. R.; TAYLOR, D. O. N. Factors influcncing mammary cancer development and postsurgical survival. Journal of the National Cancer Institute, v.43, p.12491261, 1969.

SCHUMMER, A.et al. The anatomy of the domestic animals: the circulatory sistem, the skin and the cutaneous organs of the domestic mamals. Berlin-Hamburg: Verlag Paul Parey, 1981. p.491-492.

SILVEIRA, J. M. Patologia Clínica Veterinária: teoria e interpretação. Rio de Janeiro: Guanabara-Koogan, 1988. p.98-111.

SOARES, M. P. Fisiologia da glândula mamária: aspectos comparativos. A Hora Veterinária, v.22, n.131, p.11-14, 2003.

SOAVE, T.et al. A importância do exame radiográfico torácico na abordagem de animais portadores de neoplasias. Semina: Ciências Agrárias, v.29, n.2, p.399-406, 2008.

SORENMO, K. Canine mammary gland tumors. Veterinary Clinics of North America: Small Animal Practice, v.33, p.573-596, 2006. 
SORENMO, K. U.; SHOFER, F.S.; GOLDSCHMIDT. Effect of spaying and timing of spaying on survival of dogs with mammary carcinoma. Journal of Veterinary Internal Medicine, v.14, n.3, p.266-270, 2000.

SOUZA, T. M.et al. Estudo retrospectivo de 761 tumores cutâneos em cães. Ciência Rural, v.36, p.555-560, 2006.

STONE, E. A. Neoplasias da glândula mamária. In: BIRCHARD, S. J; SHERDING, R. G.

Manual Sauders. Clínica de pequenos animais. 2.ed. São Paulo: Roca, 2003. p.246-249.

STRATMANN, N.et al, A. Mammary tumor recurrence in bitches after regional mastectomy. Veterinary Surgery, v.37, p.82-86, 2008.

SUSANECK, S. J. Feline skin tumors. Compendium of Continuing Education, v.5, n.4, p.251259, 1983.

TANAKA, N. Tumor de mama: qual a melhor conduta? Boletim Informativo, v.7, n.29, p.6-8, 2003.

TVEDTEN, H. Cytology of neoplastic and inflammatory masses. In: WILLARD, M. D.; TVEDTEN, H.; TURNWALD, G. Small animal: clinical diagnosis by laboratory methods. 2.ed. Philadelphia: WB Saunders Company, 1994. p.321- 341.

TYLER, J. Exame clínico das glândulas mamárias. In: OTTOM, R; MAYHEW, I. G. J; HOUSTON, D. M. Exame clínico e diagnóstico em veterinária. Rio de Janeiro: Guanabara Koogan, 2000. p.575-577.

VAIL, D. M.; MACEWEN, E. G. Spontaneously occurring tumors of companion animals as model for human cancer. Cancer Investigation, v.18, n.8, p.781-792, 2000.

VALLI, V. E. O. Techniques in veterinary cytopathology. In: ARNOCZKY, S.P.; FOX, P. R.; TILLEY, L. P. Seminars in veterinary medicine and surgery (small animal) - diagnostic cytology. Philadelphia: Grune \& Stratton Inc.: v.3, cap.2, p.85-93, 1988.

WELlMAN, M. L. The cytologic diagnosis of neoplasia. The Veterinary Clinics of North America. Small Animal Practice, v.20, n.4, p. 919-938, 1990.

WITHROW, S. J. Biopsy priciples. WSAVA WORD CONGRESS, 7, 1992. Anais... Roma: WSAVA, 1992. p. 1221-1226.

ZANINOVIC, P., SIMCIC, V. Z. B. Epidemiology of mammary tumours in dogs. Veterinaria Fakultaten Universite Ljubljana, v.28, p.57-72, 1991.

ZUCCARI, D. A. P. C.; SANTANA, A. E.; ROCHA, N. S. Fisiopatologia das neoplasias mamárias em cadelas - revisão. Clínica Veterinária, n.32, p.50-54, 2001 a.

ZUCCARI, D. A. P. C.; SANTANA, A. E.; ROCHA, N. E. Correlação entre a citologia aspirativa por agulha fina e a histologia no diagnóstico de tumores mamários de cadelas. Brazilian Journal of Veterinary Research and Animal Science, v.38, n.1, p.38-41, 2001b. 
